\title{
Deception and lying
}

\author{
Tony Hope Editorial Associate, Journal of Medical Ethics
}

The Japanese film director Kurosawa is best known for The Seven Samurai. However, a lesser known film of his, Ikiru (Living) tells the story of a selfish elderly man, Kanji, who develops stomach pains and visits the hospital clinic for tests. Whilst waiting for the test results he speaks with another patient - an old hand at deciphering the deceptive language of doctors. This other patient tells Kanji that if the doctors say that all is fine and that he can eat whatever he wants, then he is terminally ill. Only if the doctors advise a restricted diet is there any hope.

When Kanji sees the doctors they tell him that all is well. 'Is there no food I should avoid?' he asks hopefully. The doctors reassure him that he can eat whatever he likes. Kanji leaves the clinic certain that he is dying. The film is about the transformation in Kanji's character. Like Scrooge he turns from mean selfishness to wonderful benevolence. This transformation is unconvincing, but what affected me most when I first saw this film as a teenager was the doctors' deceit.

The extreme paternalism shown by the doctors in Kurosawa's film is now old-fashioned, at least in Britain and North America. But the issue of lying and deceiving patients remains a live one. If the boundaries have been changed, the problem of where they should be drawn still remains.

Two papers in this issue address the question of deceit. One (1) is an empirical study of nursing practice; the other (2) a theoretical analysis and case example taken from liaison psychiatry.

Ryan and colleagues first argue that no useful moral distinction can be made between lies and deceit. 'Benevolently to deceive' they write 'is to lie'. They then address the question of when it is right to lie. They identify three situations: when the lie is trivial; in the extremes of a crisis; and, in carefully defined circumstances when the patient lacks competence. They do not consider the first two situations further, although by implication they are referring to extremely rare occasions.

The purpose of their article is to spell out the conditions in the third situation by means of a case example. This case is of a female patient who has the delusional belief that she is infested with bugs under the skin. The dermatologists want a psychiatric opinion and the expectation is that anti-psychotic medication has a good chance of treating the delusions. The problem is that past experience has shown that she will not see a psychiatrist. If she knows that the person seeing her is a psychiatrist she will run away and lose contact with the medical services.

The authors argue that under these conditions it would be right to lie. It would be right for a psychiatrist to see her and if asked: 'Are you a psychiatrist?' to answer 'No'.

The argument they make is not simply that the benefit of treatment to the patient justifies the lie. They give great weight to respect for autonomy, and in general lies and deceit do not respect autonomy. Thus, if she were offered anti-psychotic medication and asked in detail about the side-effects, it would not, according to Ryan and colleagues, be right to lie about these side-effects, even if the truth would lead to her refusing the medication. Their reason is that she is competent to understand the side-effects - her delusion does not interfere with such understanding. They argue that lying could be justified only if the patient could not make an informed decision on a particular matter as a direct result of the delusion.

Lying about the side-effects is wrong, they argue, because 'Nothing about her illness makes her incompetent on the side-effect front'. However, lying about the mode of action of anti-psychotic medication may be justified because the patient would refuse as a direct result of the delusion. For the same reason it may be right to lie about being a psychiatrist.

Apart from this one type of exception Ryan and colleagues take a strong line against deceit and lying. But how do health staff actually behave? Teasdale and Kent asked 251 nurses to describe a situation where they had tried to relieve a patient's anxiety. Out of the 251 reported incidents, ten involved deception. They asked about these in detail.

The value of this kind of empirical work is that it tests both theory and practice. A theoretically attractive stance may be found wanting in the light of real situations. Nurses may be deceiving patients with good reason. On the other hand accepted 
practice may, when examined critically, be wrong, or even abusive, to patients.

So how do the real examples stand up to the theoretical analysis? Ryan and colleagues argue that deceit or lying to a competent patient is almost never justified. Four of Teasdale and Kent's examples relate to fully competent patients. Two involved deceiving patients about their poor prognosis. A third example was of a nurse who withheld information from a patient about the degree of likely pain following an operation to the hand. In these three cases, subsequent events suggested that the deceit was resented by the patients.

The fourth case concerned a man whose dog had been put down by a friend, following the man's admission to hospital. The man was waiting to go to sheltered accommodation where they didn't allow pets. When he asked about his dog the nurse reassured him that he would see it at some stage. The outcome of this deception is unknown.

The six other incidences involved patients with impaired intellectual abilities, confusional states or mental handicap. One example was of a woman whom I imagine was suffering from dementia and who kept asking about going home (which was not possible). The nurse told her that she couldn't go home that day as there was no transport on a Sunday and lied that her daughter would be coming in later to see her.

Another example was of a patient with learning disabilities, who was going to be moved to live in a new bungalow. However, in order to stop him becoming anxious, the staff lied to him, saying that he would not be going to the new bungalow.

The analysis of Ryan and colleagues focuses on situations where patients make decisions. Their analysis is not directly applicable to the real situations described by Teasdale and Kent where the deceit was aimed at reducing distress rather than at influencing a decision. But what does seem clear is that the arguments of Ryan and colleagues support a degree of truthfulness that is more rigorous than much clinical practice. In the first place they consider that deceit is as bad as lying and in the second place they uphold truth-telling even in circumstances where lying would benefit the patient.

But does their position go far enough? I remain unhappy with their example. I believe the patient's autonomy has been breached and the deceit is wrong. In the example, the patient understands the meaning of 'I am not a psychiatrist'. Her delusions do not interfere with this understanding. Consider why she might be refusing to see a psychiatrist. One reason is that it would not do any good because she believes that her problem is a dermatological one. But there might be other reasons: perhaps no wanting to be labelled as mentally ill; perhaps a fear of psychiatrists; perhaps some earlier experiences which have led to a dislike of psychiatrists.

If, because of the lie, she talks to the psychiatrist believing him to be a dermatologist, her autonomy has been breached. She has been wronged. This is not necessarily to say that it is wrong to lie - the lie may be justified by the result it brings (her accepting treatment). But this lie is in the same category as deceit about the side-effects.

I remain, however, unhappy about this lie, just as Ryan and colleagues are unhappy about lying over side-effects. If her suffering justifies treatment without her assent I would prefer to treat her compulsorily, telling her the truth, than to gain her assent through deceit.

Tony Hope, MA, PhD, MRCPsych, is Editorial Associate of the Journal of Medical Ethics. He is a psychiatrist and Leader of the Oxford Practice Skills Project at Oxford University.

\section{References}

(1) Teasdale K, Kent G. The use of deception in nursing Fournal of medical ethics 1995; 21: 77-81.

(2) Ryan C J, de Moore G, Patfield M. Becoming none but tradesmen: lies, deception and psychotic patients. Fournal of medical ethics 1995; 21: 72-76. 